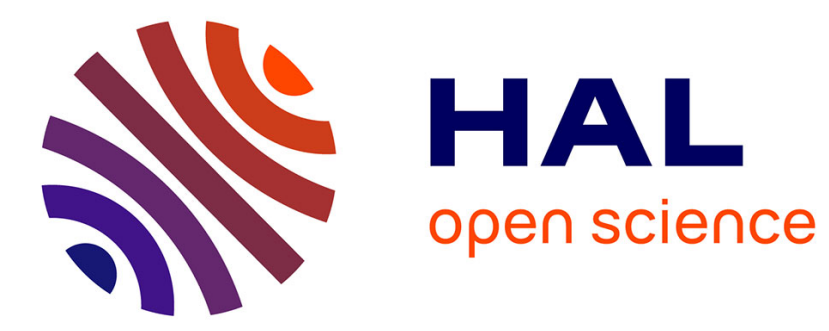

\title{
Plastic yielding of glass in high-pressure torsion apparatus
}

Linfeng Ding, Michael Kerber, Clemens Kunisch, Boris J.P. Kaus

\section{To cite this version:}

Linfeng Ding, Michael Kerber, Clemens Kunisch, Boris J.P. Kaus. Plastic yielding of glass in highpressure torsion apparatus. International Journal of Applied Glass Science, 2019, 10 (1), pp.17-26. hal-01969247

\section{HAL Id: hal-01969247 \\ https://hal.science/hal-01969247}

Submitted on 3 Jan 2019

HAL is a multi-disciplinary open access archive for the deposit and dissemination of scientific research documents, whether they are published or not. The documents may come from teaching and research institutions in France or abroad, or from public or private research centers.
L'archive ouverte pluridisciplinaire HAL, est destinée au dépôt et à la diffusion de documents scientifiques de niveau recherche, publiés ou non, émanant des établissements d'enseignement et de recherche français ou étrangers, des laboratoires publics ou privés.

\section{(1) (1) $\$$}

Distributed under a Creative Commons Attribution - NonCommercial - NoDerivatives 44.0 


\title{
Plastic yielding of glass in high-pressure torsion apparatus
}

\author{
Linfeng Ding ${ }^{1 *}$, Michael Kerber ${ }^{2}$, Clemens Kunisch ${ }^{3}$, Boris J.P. Kaus ${ }^{1}$ \\ ${ }^{1}$ Institute of Geosciences, Johannes Gutenberg University, 55128 Mainz, Germany \\ ${ }^{2}$ Research Group Physics of Nanostructured Materials, University of Vienna, A-1090 Vienna, Austria \\ ${ }^{3}$ Schott AG, Corporate Research \& Development, 55122 Mainz, Germany \\ *Corresponding author: dingli@uni-mainz.de
}

\begin{abstract}
Hardness measurements performed at room temperature have demonstrated that glass can flow under elevated pressure, whereas the effect of high pressure on glass rheology remains poorly quantified. Here, we applied a high-pressure torsion (HPT) apparatus to deform SCHOTT SF6 ${ }^{\circledR}$ glass and attempted to quantify the effect of pressure and temperature on the shear deformation of glass subjected to pressures from $0.3 \mathrm{GPa}$ to $7 \mathrm{GPa}$ and temperatures from $25{ }^{\circ} \mathrm{C}$ to $496{ }^{\circ} \mathrm{C}$. Results show that the plastic yield deformation was occurring during the HPT experiments on the SF6 glass at elevated temperature from $350{ }^{\circ} \mathrm{C}$ to $496{ }^{\circ} \mathrm{C}$. The yield stress of SF6 glass decreases with increasing temperature and decreasing pressure. An extended Arrhenius model with one set of parameters, namely infinite yield stress $Y_{0}=0.17 \pm 0.1 \mathrm{GPa}$, activation energy $E_{a}=4.8 \pm 0.5 \mathrm{~kJ} / \mathrm{mol}$ and activation volume $V_{a}=1.4 \pm 0.2 \mathrm{~cm}^{3} / \mathrm{mol}$, can explain the experimental results well.
\end{abstract}

Keywords: Plastic yielding; glass flow; pressure; high-pressure torsion. 


\section{Introduction}

The viscosity of glass at different temperature regions under ambient pressure has been well studied ${ }^{1}$, and numerous models for the temperature dependence of viscosity have been developed that fit the experimental data well'2,3,4, 5, 6, 7, 8 . On the other hand, hardness measurements ${ }^{9}, 10,11$ performed at room temperature have demonstrated that glass can flow at room temperature under elevated pressure. Yet the actual pressure level and its distribution in the glass underneath an indenter and its consequences on the mechanical behavior remain poorly understood ${ }^{12,13}$.

The importance of understanding both the temperature and the pressure dependence of the viscosity of the glass is connected to the fact that density strongly relates to the dynamics of the fluid ${ }^{14}$. Several experimental and modeling studies focused on the effect of pressure on the viscosity of glass $15,16,17,18,19,20,21$. In our previous work ${ }^{22}$, the effect of pressure on density and volume recovery of SCHOTT $\mathrm{N}-\mathrm{BK} 7^{\circledR}$ glass has been studied, and a two-internal-parameter relaxation model was developed, that predicts a linear increase of viscosity with pressure. Moreover, uniaxial deformation experiments ${ }^{23}$ on SCHOTT N-BK $7^{\circledR}$ glass have also been performed in a Paterson press ${ }^{24}$, which is an argon gas medium hot press with a compression deformation mechanism, are in general agreement with the prediction of the two-internal-parameter relaxation model $^{22}$ at the pressure range of $0.1 \mathrm{GPa}-0.3 \mathrm{GPa}$.

On the other hand, viscous flow is not the only deformation mechanism for materials under high pressure. A deformation via plastic yield is widely reported in many 
deformation experiments on polymers ${ }^{25}$, alloys ${ }^{26}$, and metallic glass ${ }^{27,28}$. The atomistic origin for the plastic yield criterion for metallic glass under pressure is discussed by Schuh $\&$ Lund $^{29}$, which generally supports the plastic yield behavior in amorphous materials. Amorphous materials, including glass, lack the microstructural defects which facilitate plastic flow in crystalline materials, and thus potentially have a much higher yield stress in a plastic yield deformation, e.g., up to $3 \mathrm{GPa}$ for oxide glass ${ }^{30}$ and $\sim 0.5 \mathrm{GPa}^{31}$ to 5 $\mathrm{GPa}^{32}$ for metallic glass. However, industrial oxide glass typically has a low fracture toughness, on the order of $1 \mathrm{MPa} \cdot \mathrm{m}^{0.5}$, and consequently, brittle fractures usually occur much earlier than plastic yielding.

High-pressure torsion (HPT) is a well-known method to induce severe plastic

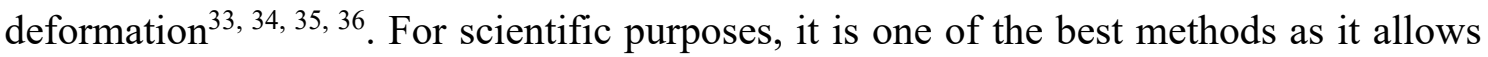
for the controlled generation of high pressures and large strains at a number of exterior physical parameters such as strain rate and temperature. Thus, HPT is ideal for highly reproducible experiments under rather extreme conditions. To the knowledge of the authors, the HPT deformation experiments have not yet been conducted on an optical glass before. In this work, we applied HPT to deform the SCHOTT SF6 ${ }^{\circledR}$ optical glass by torsion at very low rotations speeds and at different temperatures to study the flow of glass under high pressure and as a function of temperature.

\section{Experimental}

\subsection{Samples}


The alkali-lead-silicate glass SCHOTT SF6 ${ }^{\circledR}$ (chemical composition ${ }^{37}: 27.3 \% \mathrm{SiO}_{2}$, $1.5 \% \mathrm{~K}_{2} \mathrm{O}, 71 \% \mathrm{PbO}$ ) is an optical glass widely used as photonic crystal fiber ${ }^{38,39,40}$ for efficient spectral broadening at high repetition rates (several GHz). The density of SCHOTT SF6 $^{\circledR}$ glass at room temperature and ambient pressure is $5.180 \pm 0.001 \mathrm{~g} / \mathrm{cm}^{3}$. The glass transition temperature $\mathrm{T}_{\mathrm{g}}$ of the SCHOTT SF $6{ }^{\circledR}$ glass is $417^{\circ} \mathrm{C}$, which is the temperature at which the viscosity is $12 \log _{10}(\mathrm{~Pa} \cdot \mathrm{s})$. The SCHOTT SF $6^{\circledR}$ glass specimens with diameters of $6.0 \pm 0.02 \mathrm{~mm}$ and $10.0 \pm 0.02 \mathrm{~mm}$ and thickness of $0.54 \pm 0.02$ and $0.62 \pm 0.02 \mathrm{~mm}$ were used for the HPT experiments. All glass specimens were ground with a $59 \mu \mathrm{m}$ sandblast grinding apparatus resulting in uniform surfaces and edges. The surface and edge condition of the glass specimens were investigated under the microscope, and one example of SF $6^{\circledR}$ glass is shown in Fig. 1 (b).

The composition dependence of glass rheology is not the topic we study in this work. We choose SCHOTT SF6 ${ }^{\circledR}$ glass for these experiments mainly due to its low glass transition temperature combined with the good stability of the material properties. The temperature limit for the present HPT setup is $\sim 540{ }^{\circ} \mathrm{C}$ due to the softening of the anvil steel Boehler S390 MC around that temperature in combination with the loads applied. The SCHOTT N-BK7 ${ }^{\circledR}$ glass used in our previous work $^{22,23}$ with $\mathrm{T}_{\mathrm{g}}=561{ }^{\circ} \mathrm{C}$ is not suitable for the HPT deformation experiments. 
(a)

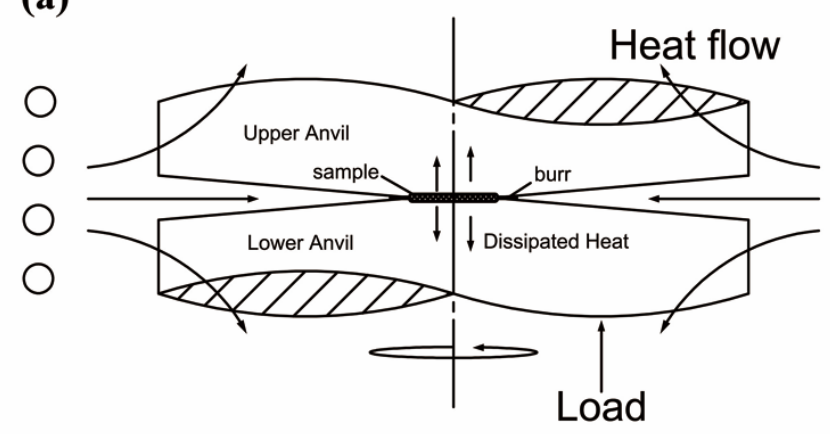

(b)

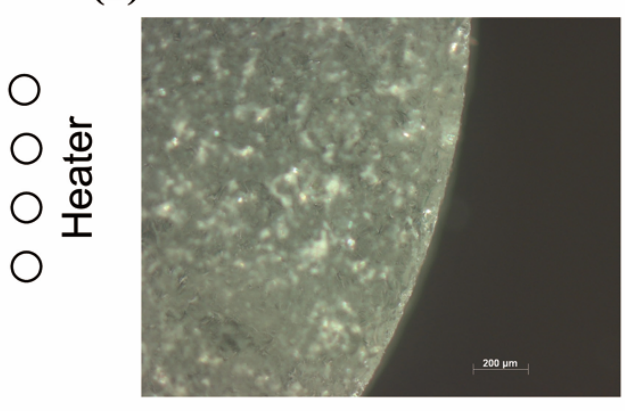

Fig.1 (a) Schematic graph of high-pressure torsion apparatus in this work; (b)

Microscope image of the glass sample.

\subsection{Test equipment and experimental process}

The high-pressure torsion (HPT) apparatus used in these experiments is a Klement HTP pre-series machine, with the same basic design as described in Vorhauer et al. ${ }^{34}$ and Wetscher et al. ${ }^{41}$, a sketch of the principle of operation of HPT is shown in Fig.1 (a). Two anvils are pressed against each other with the (glass) sample in between thus applying a hydrostatic pressure. The contact surfaces between sample and anvil can be both flat (unconstrained HPT), both with identical cavities or with asymmetric cavities (quasiconstrained HPT). The unconstrained HPT configuration is most similar to a classical rheometer, whereas the symmetric cavities are most common and correspond closest to a true hydrostatic loading of the sample. During the initial uniaxial compression, a burr forms in the gap between the anvils on the rim of the cavity providing a sealing of the sample as well as preventing the anvils from touching which results in the measurement of the friction of the anvils instead of the load on the samples. In the present case for a proper formation of the burr, the total depth of both cavities was determined to be 
approximately $20 \%$ smaller than the thickness of the glass sample. With this experimentally determined value, only a small amount of the material freely flows into the burr during the initial part of the experiment.

After the application of pressure, the lower anvil is rotated at nominal 0.01 rounds per minute (RPM), which causes the sample to transmit a torque on the upper anvil and its holder. A self-built torque-sensor consisting of four strain-gauge half-bridges from HBM connected to two full bridges in averaging configuration is used to measure the torque needed to deform the sample. Before each set of experiments, the raw physical value $(\mathrm{mV} / \mathrm{V})$ of the strain-gauge signal was calibrated using a standard Gedore torquewrench at $50 \mathrm{Nm}$ and $100 \mathrm{Nm}$, with a limiting precision of $2 \%$ without any pressure applied. The calibration was also monitored randomly between experiments. The effect of the hydrostatic loading on the torque signal (zero-shift) was also recorded (it is smaller than one percent) and subtracted from the signal before evaluation.

The hydrostatic load was recorded as the pressure in the piston and as the load transmitted via the sample to an HBM C2A load-cell directly in N. The present machine is designed to provide controlled pressure application from 1-10 GPa, depending on the sample diameter.

In this work, firstly, a set of $6 \mathrm{~mm}$ diameter glass samples was used to investigate the pressure range from $\sim 3 \mathrm{GPa}$ to $\sim 7 \mathrm{GPa}$. A second set, with improved torque-sensor and the cooling system, aimed to achieve lower pressures by using $10 \mathrm{~mm}$ samples for pressures from $\sim 1 \mathrm{GPa}$ to $\sim 3 \mathrm{GPa}$ (by automatic loading). Also using $10 \mathrm{~mm}$ samples for 
$\sim 0.3 \mathrm{GPa}$ pressure were obtained by manual loading, bypassing computer control of the pressure.

An important parameter in the present case is the sample temperature: Heating was performed using a Hüttinger induction heater, symmetrically heating the anvils. The temperature control and monitoring were done by using a Sensortherm pyrometer with a control unit capable of detecting temperatures above $75{ }^{\circ} \mathrm{C}$. The control window of the setup is below $0.5^{\circ} \mathrm{C}$. A reference measurement using a thermocouple in a copper disc in place of the sample showed that the sample lags at most two minutes behind the Pyrometer data (large deviation at low temperatures). The overall uncertainty of the temperature is about $\pm 5^{\circ} \mathrm{C}$.

The procedure of the current experiment was as follows: firstly, both cavities of the two anvils were sandblasted with 250 microns quartz sand. Then, the glass specimen was placed in the lower anvil and lifted to a bare touch of the upper anvil, and the samples were heating to the initial temperatures ranging from $350{ }^{\circ} \mathrm{C}$ to $496^{\circ} \mathrm{C}$. After waiting the experimentally determined two minutes, the pressure from $0.3 \mathrm{GPa}$ to $7 \mathrm{GPa}$ was applied via uniaxial loading. Finally, the deformation was started with the nominal speed of 0.01 RPM, which turned out to be 0.0096 RPM as calculated from the data recorded over several minutes.

To verify the reproducibility of the data, for each sample heating cycles were performed, between the chosen temperatures thus checking the consistency per sample. Additionally, the whole experiment was repeated on another sample. 
Furthermore, an experiment at room temperature and a pressure of $3 \mathrm{GPa}$ was also performed. In order to be able to compare with measurements in a rheometer and to judge the effect of the burr, also flat anvils were used for one deformation.

To isolate the effect of the pressure on the torque one experiment at $435^{\circ} \mathrm{C}, 10 \mathrm{~mm}$ diameter sample was performed, stepwise increasing the pressure from 0.3 to $5.1 \mathrm{GPa}$ once the torque readout stabilized.

\subsection{Data analysis}

For a torsional deformation, the glass sample could be deformed as a viscous flow ${ }^{1}$ or via a plastic yielding ${ }^{29}$.

\subsubsection{Approach 1: viscous flow}

For a viscous flow, the viscosity is constant when the deformation reaches steady state, and the viscous strain rate, stress, and viscosity can be calculated by

$$
\begin{aligned}
& \dot{\varepsilon}(r)=\frac{2 \pi r f}{H} \\
& \tau(r)=\eta \dot{\varepsilon}(r)=\eta \frac{2 \pi r f}{H} \\
& M_{T}=\int_{0}^{R} 2 \pi r \cdot \tau(r) \cdot r d r=\frac{\eta \pi^{2} R^{4} f}{H} \\
& \eta=\frac{M_{T} H}{\pi^{2} R^{4} f}
\end{aligned}
$$

where $\dot{\varepsilon}(r)$ is the change of strain with time at a radius $r, \tau(r)$ is the shear stress at a radius $r, \eta$ is the viscosity, $M_{T}$ is the measured torque, $f$ is the frequency of the rotation (converted to SI-units via RPM/60), $H$ is the thickness of the sample, and $R$ is the outer radius of the sample. 


\subsubsection{Approach 2: shear yielding}

For a yield deformation, the shear yield stress $Y$ is not dependent on the radius, and therefore

$$
\begin{aligned}
& M_{T}=\int_{0}^{R} 2 \pi r \cdot Y \cdot r d r=\frac{2 \pi R^{3} Y}{3} \\
& Y=\frac{3 M_{T}}{2 \pi R^{3}}
\end{aligned}
$$

And the friction coefficient can be calculated as

$$
\mu=\frac{Y}{P}
$$

where $\mathrm{P}$ is the uniaxial pressure (normal stress).

\section{Results}

The experimental conditions and the measured mechanical data are provided in Table 1. The number of the aforementioned repetition stages per experiment and their changes, as well as the resulting deviation of the measured values together with the nominal, identical experimental parameters, are reported in Table 1.

Most importantly, torsional experiments could be performed on SCHOTT SF6 ${ }^{\circledR}$ glass under pressures from $0.3 \mathrm{GPa}$ to $7.4 \mathrm{GPa}$, the work necessary to maintain the deformation could be monitored accurately via the torque measured as shown in Fig.2. The experiments at $435{ }^{\circ} \mathrm{C}$ (black curve) show that the torque increases approximately proportional to the pressure from $137 \mathrm{~N} \cdot \mathrm{m}$ at $1.1 \mathrm{GPa}$ to $307 \mathrm{~N} \cdot \mathrm{m}$ at $5.1 \mathrm{GPa}$. However, in another experiment at a pressure of $7.4 \mathrm{GPa}$, the measured torque at $435{ }^{\circ} \mathrm{C}$ increased dramatically high to nearly $776 \mathrm{~N} \cdot \mathrm{m}$. Subsequent visual inspection of sample and anvils, 
showed that the top and bottom anvils had touched together at this high pressure, and a clear deformation band of approximately $18 \mathrm{~mm}$ in place of the rims of the cavities had appeared, as is visible in Fig.2.

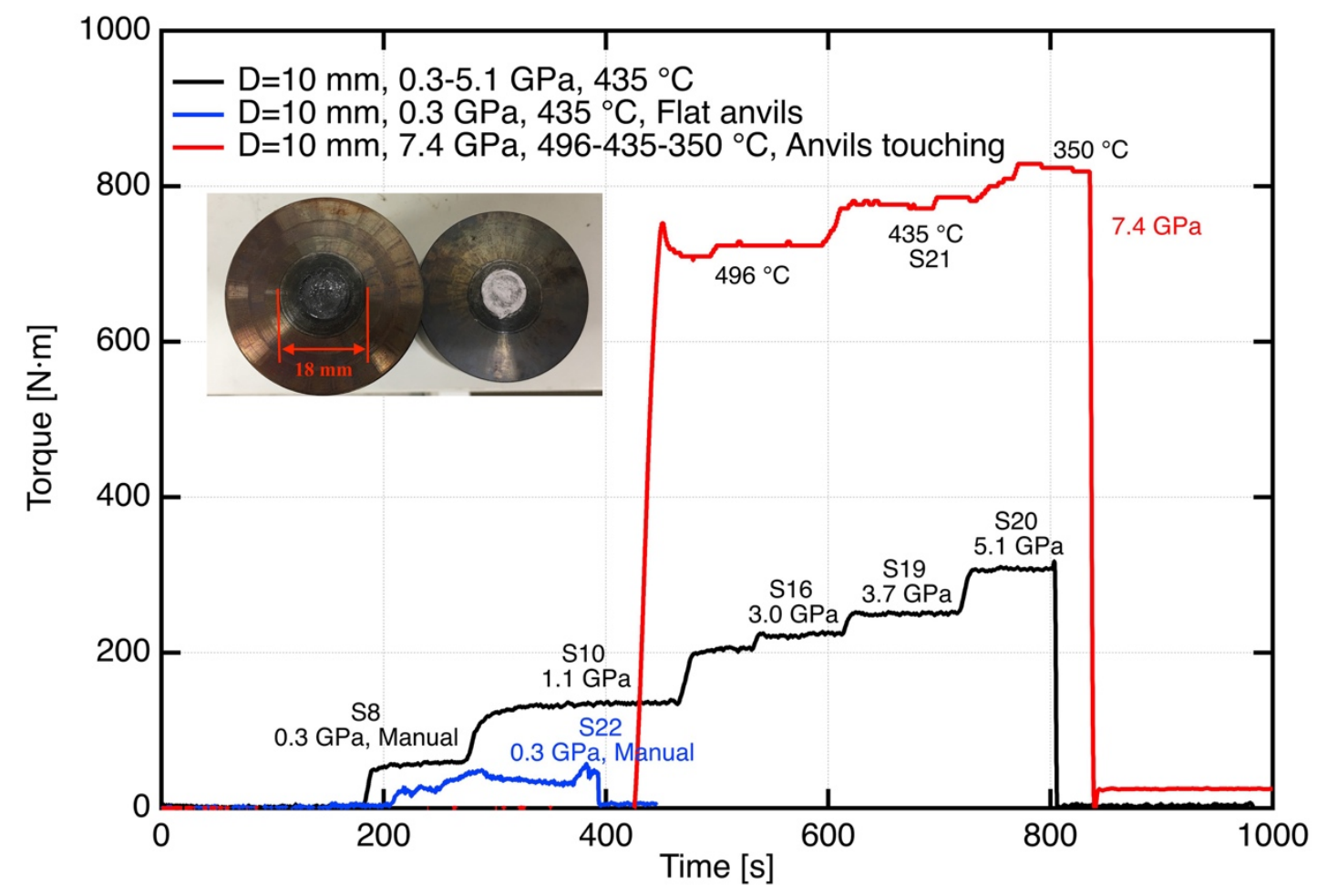

Fig.2 Mechanical torque curves of SF6 glass measured at different pressures and setups.

The digital photo shows the status of anvils after the experiment at $7.4 \mathrm{GPa}$ (red curve).

The bottom piston of the HPT with anvil diameter of $10 \mathrm{~mm}$ could automatically lift and smoothly deform the sample at the pressure above $1 \mathrm{GPa}$. To obtain a lower pressure, the bottom piston was manually lifted until a load was detected by the upper load sensor, corresponding to $0.3 \mathrm{GPa}$, and subsequently, the deformation was started. To better judge the torque measurements via HPT in the current context, two anvils were machined to flat 
surfaces, allowing an experiment in the HPT equipment with the ideal rheometry configuration. The flat-anvil measurement reported in Fig.2 reaches a similar torque value as the one measured with the quasi-constrained setup (with burrs). However, the curve also shows that the deformation was not as stable as for the higher pressures, most likely connected with some sliding occurring.

The raw torque curves from the HPT deformation measurements are shown in Fig.3. The deformation experiments at a constant torsional speed of 0.0096 RPM and different temperatures, pressures and anvil diameters reach steady state torques from $\sim 50 \mathrm{~N} \cdot \mathrm{m}$ to $\sim 275 \mathrm{~N} \cdot \mathrm{m}$. To determine the pressure dependence, we conducted automatic loading experiments at uniaxial pressures ranging from $\sim 1 \mathrm{GPa}$ to $\sim 7 \mathrm{GPa}$. At the same temperature, the torque is approximately increasing linearly with elevated pressure of $\sim 40$ $\mathrm{N} \cdot \mathrm{m} / \mathrm{GPa}$ using $10 \mathrm{~mm}$ samples and $\sim 15 \mathrm{~N} \cdot \mathrm{m} / \mathrm{GPa}$ for $6 \mathrm{~mm}$ samples. 


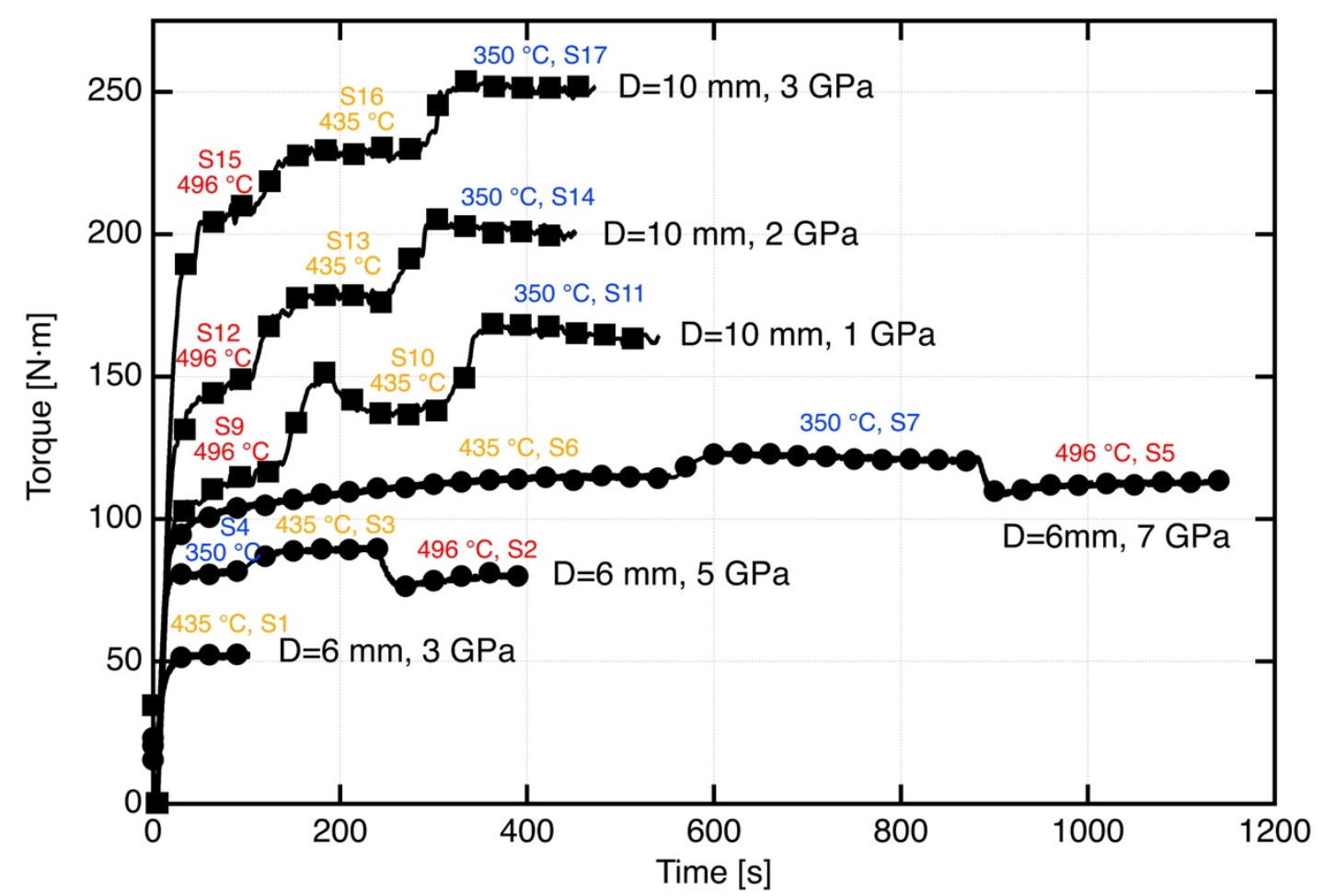

Fig.3 Original mechanical torque data from the HPT measurements of SF6 glass. For all curves, 1 data point out of every 600 points is shown for clarity.

An overview of the temperature dependence is well observable in Fig.3. At the same pressure, the temperature reduction from $496{ }^{\circ} \mathrm{C}$ to $435{ }^{\circ} \mathrm{C}$ is accompanied by a torque increase of around $25 \mathrm{~N} \cdot \mathrm{m}$ is observed in the setup of $10 \mathrm{~mm}$ anvils. The temperature decrease from $435{ }^{\circ} \mathrm{C}$ to $350{ }^{\circ} \mathrm{C}$ is accompanied by a torque increase of around $27 \mathrm{~N} \cdot \mathrm{m}$. However, the significant temperature change yields only slight influence on the torque measurements in $6 \mathrm{~mm}$ setup. Besides, the torque does not even change significantly when the glass sample is quenched to room temperature.

The torsional experiment was also done at room temperature at $3 \mathrm{GPa}$, during which a big cracking noise was heard at the beginning of the deformation. A clear yielding point 
in the torque data of approximately $185 \mathrm{~N} \cdot \mathrm{m}$ is seen in Fig.4. After the yielding point, the torque is gradually decreasing to around $164 \mathrm{~N} \cdot \mathrm{m}$ and reaches steady state. It must be noted that the torque measured at room temperature at $3 \mathrm{GPa}$ is even $\sim 40 \mathrm{~N} \cdot \mathrm{m}$ lower than at $496{ }^{\circ} \mathrm{C}$. A pause test was done in this experiment by stopping the rotation of the HPT machine. The torque subsequently decreased gradually, and it recovered to the same level (as before the pause) once the deformation was turned on. After the deformation, a large amount of fine glass powder generated in the anvil (especially the burr area) was observed. A possible explanation of this experiment is discussed in the shear yielding part.

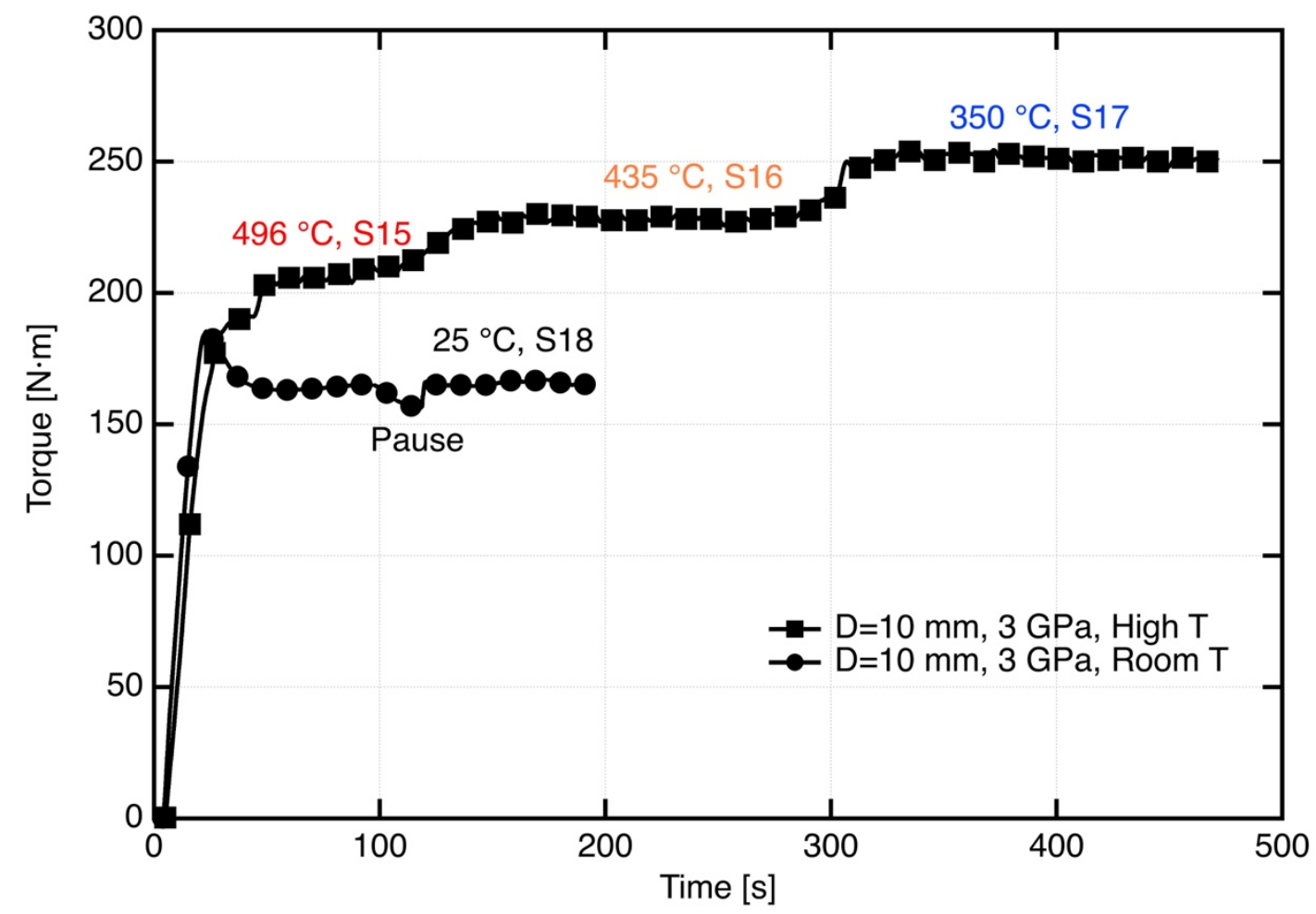

Fig.4 Torque measurement of SF6 glass at room temperature and high temperatures under $3 \mathrm{GPa}$. For all curves, 1 data point out of every 220 points is shown for clarity. 


\section{Discussions}

\subsection{Approach 1: viscous flow}

Assuming that viscous flow is the predominant deformation mechanism in the present experiments on SCHOTT SF ${ }^{\circledR}$ glass, the corresponding viscosity was calculated. The 3D plot in Fig.5 gives an overview of the temperature and pressure dependence of the HPT torque evaluated viscosity of SF6 glass. The temperature change from $350{ }^{\circ} \mathrm{C}$ to $496{ }^{\circ} \mathrm{C}$ is accompanied by a maximal torque evaluated viscosity change from 10.8 $\log _{10}(\mathrm{~Pa} \cdot \mathrm{s})$ to $11.7 \log _{10}(\mathrm{~Pa} \cdot \mathrm{s})$ only, which is entirely different to the black curve at ambient pressure, where the change is from $16.2 \log _{10}(\mathrm{~Pa} \cdot \mathrm{s})$ to $8.0 \log _{10}(\mathrm{~Pa} \cdot \mathrm{s})$. Indeed, the influence of the pressure on the viscosity is rather small of only approximately 0.1 $\log _{10}(\mathrm{~Pa} \cdot \mathrm{s}) / \mathrm{GPa}$. Specifically, the viscosity of SF6 at $435{ }^{\circ} \mathrm{C}$ and $1 \mathrm{GPa}$ is 10.87 $\log _{10}(\mathrm{~Pa} \cdot \mathrm{s})$, which is even slightly lower than the viscosity at $435{ }^{\circ} \mathrm{C}$ at 1 -atm of 11.01 $\log _{10}(\mathrm{~Pa} \cdot \mathrm{s})$. 


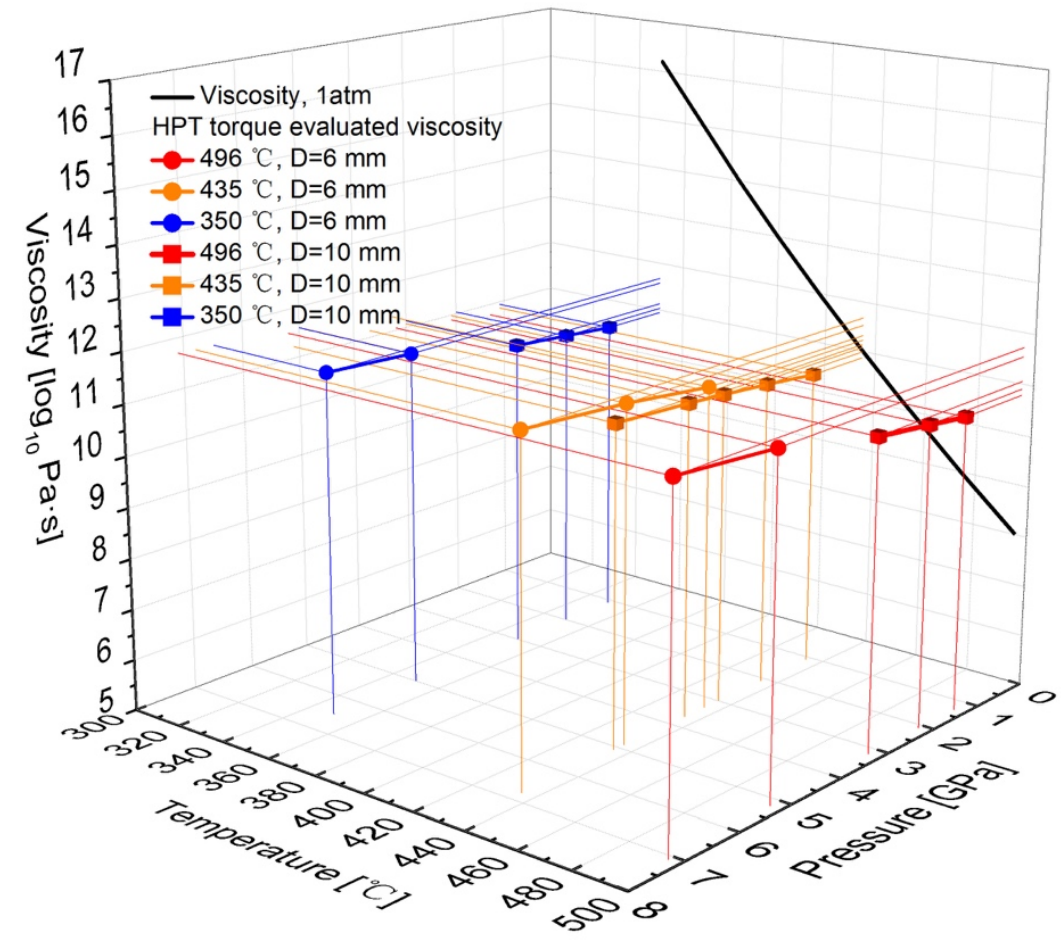

Fig.5 HPT torque evaluated viscosity-temperature-pressure 3D plotting of SF6 glass samples compared to the viscosity at 1-atm.

To answer the question if the viscous flow dominates the HPT deformation of SF6 glass, as well as to explain the experimental data, consider the following two cases:

\subsubsection{Viscous flow induced by dissipative heating}

A significant temperature increase can occur during HPT deformation, depending on the rotation speed ${ }^{42,43}$. The high pressure (load) may produce viscous heating, and therefore have similar equivalent viscosities, independent of the ambient parameters. If we assume a pure viscous shear heating, the dissipative heating rate is

$$
q_{d i s s}=\int_{0}^{R} 2 \pi r \cdot \tau(r) \cdot \dot{\varepsilon}(r) \cdot d r \cdot H=\frac{2 \eta \pi^{3} R^{4} f^{2}}{H}=2 \pi f M_{T}
$$


which under stationary thermal conditions has to be equal to the dissipative heat loss rate of

$$
q_{\text {loss }}=q_{\text {diss }}=\kappa A \Delta T_{\text {diss }}
$$

where $\kappa$ is the heat transfer coefficient depending on the material and cooling rate of anvils, $W /\left(m^{2} K\right), \mathrm{A}=2 \pi R^{2}$ is the heat transfer area (upper and lower sample surfaces), and $\Delta T_{\text {diss }}=T_{\text {sample }}-T_{\text {measured }}$ is the additional temperature difference between the sample the temperature reference point. We assume a $\kappa$ of $37 \mathrm{~W} /\left(\mathrm{m}^{2} \mathrm{~K}\right)$ for all the SF6 glass experiments and calculate the dissipative shear heating induced temperature increase reported in Fig.6. The calculated temperature increase is too low for some of the measurements at $350{ }^{\circ} \mathrm{C}$ and too high for some of the measurements at $496{ }^{\circ} \mathrm{C}$. Thus, this simple assumption with a constant $\kappa$ does not explain all measurement results. We expect that the overall result does not change if we account for the change of material properties at elevated pressure. Therefore, we stay at the simplest calculation with a constant $\kappa$. 


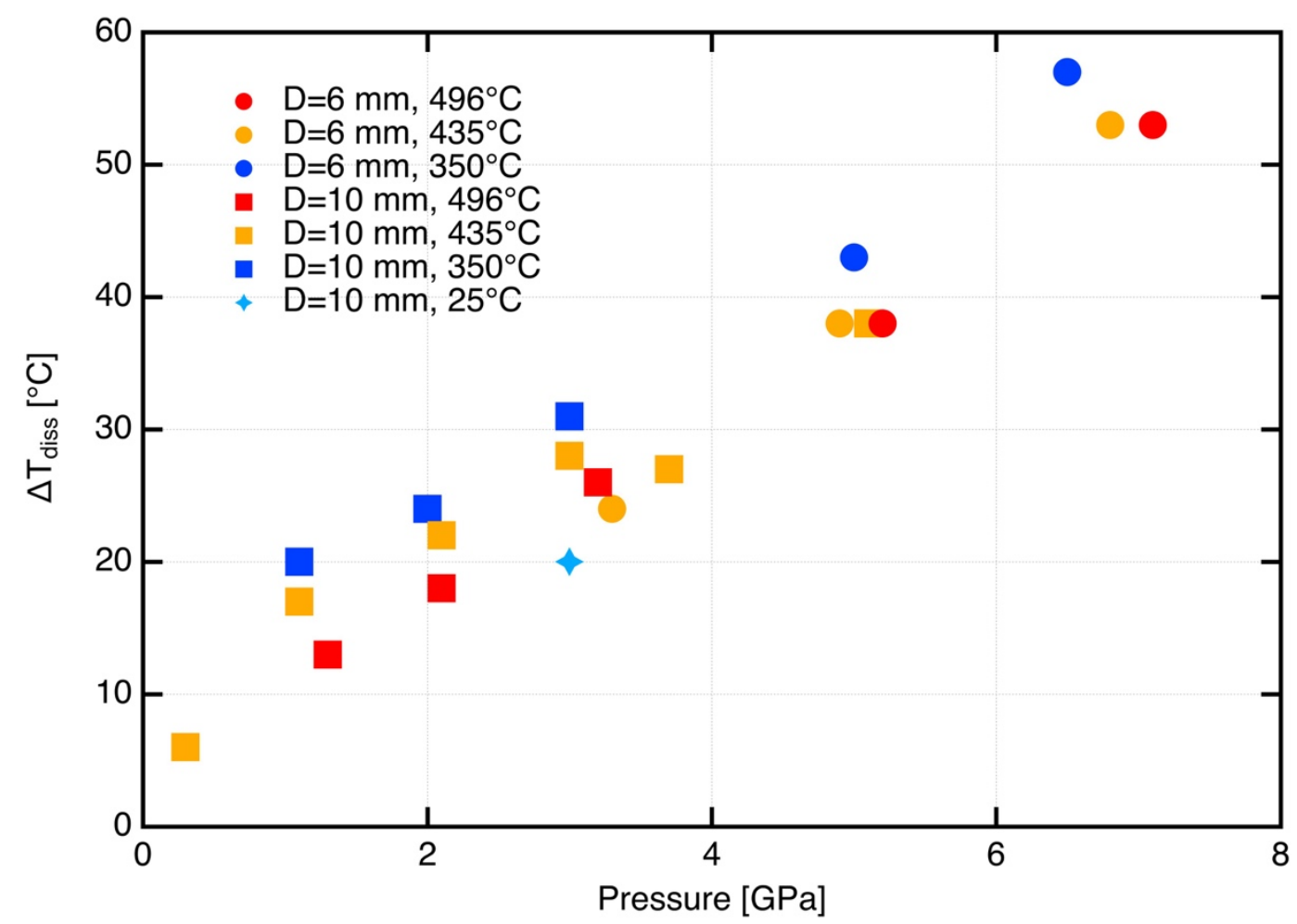

Fig.6 Calculated dissipative shear heating induced temperature increase of SF6 glass as a function of pressure $\left(\kappa=37 \mathrm{~W} /\left(\mathrm{m}^{2} \mathrm{~K}\right)\right)$.

Additionally, the experiments were performed at a nominal deformation speed of 0.01 RPM. Extrapolating the Results from Edalati et al. ${ }^{42}$ and Zhilyaev \& Langdon $^{43}$ to the speed we applied in this work shows only small heating is to be expected. Using the Vickers hardness $\mathrm{HV}=3.6 \mathrm{GPa}$ and omega $=f=0.0096 \mathrm{RPM}$ for the present case gives only $2{ }^{\circ} \mathrm{C}$ heating at $2 \mathrm{GPa}$ and $7{ }^{\circ} \mathrm{C}$ heating at $6 \mathrm{GPa}$.

In summary, viscous flow induced by dissipative heating is not the main mechanism for the deformation of SF6 glass via HPT.

4.1.2 Viscous flow induced by elastic energy 
The elastic energy which is greatly influenced by pressure might also govern the viscous flow of glass in our work. The elastic energy in HPT consists of the elastic shear stress (deviatoric), and the hydrostatic stress (volumetric). $E_{1}$ accounts for the shear stress (deviatoric)

$$
\frac{1}{H} E_{1}=\int_{0}^{R} 2 \pi r \cdot \frac{1}{2} \sigma_{x y} \delta_{x y} \cdot d r=\int_{0}^{R} 2 \pi r \cdot \frac{1}{2 G}\left(\eta \frac{2 \pi r f}{H}\right)^{2} \cdot d r=\frac{M_{T}{ }^{2}}{\pi G R^{4}}
$$

where $\mathrm{R}, \mathrm{H}, f, M_{T}$ and $\eta$ are the same as in section 2.3, $\sigma_{x y}$ is the shear stress, $\delta_{x y}$ is the shear strain, $G$ is the shear modulus.

And $E_{2}$ accounts for the hydrostatic stress (volumetric). In this work, we assume

$$
\frac{1}{V} E_{2}=\frac{1}{2} \sigma_{h y d} \varepsilon_{h y d}=\frac{1}{2} \frac{P^{2}}{K_{r e f}}
$$

where $\sigma_{h y d}$ is the hydrostatic stress, $\varepsilon_{h y d}$ is the bulk strain, $P$ is the hydrostatic pressure, $K_{r e f}$ is the reference bulk modulus at ambient pressure.

Thus, we obtain the total elastic energy:

$$
\frac{1}{V} E=\frac{1}{V} E_{1}+\frac{1}{V} E_{2}=\frac{M_{T}^{2}}{\pi^{2} G R^{6}}+\frac{1}{2} \frac{P^{2}}{K_{r e f}}
$$

To assess the equivalent temperature increase $\Delta T_{\text {elas }}$,

$$
E=\rho C_{p} \Delta T_{\text {elas }}
$$

is used, where $\rho$ is the density measured at room temperature and pressure, and $C_{p}$ is the heat capacity measured at room temperature and pressure. The resulting $\Delta T_{\text {elas }}$ as a function of pressure shown in Fig.7. The calculated equivalent temperature increase at pressures lower than $3 \mathrm{GPa}$ is smaller than $85^{\circ} \mathrm{C}$ which cannot explain the data. Therefore, viscous flow activated by elastically stored energy is thus also not the main mechanism for the deformation of SF6 glass via HPT. 


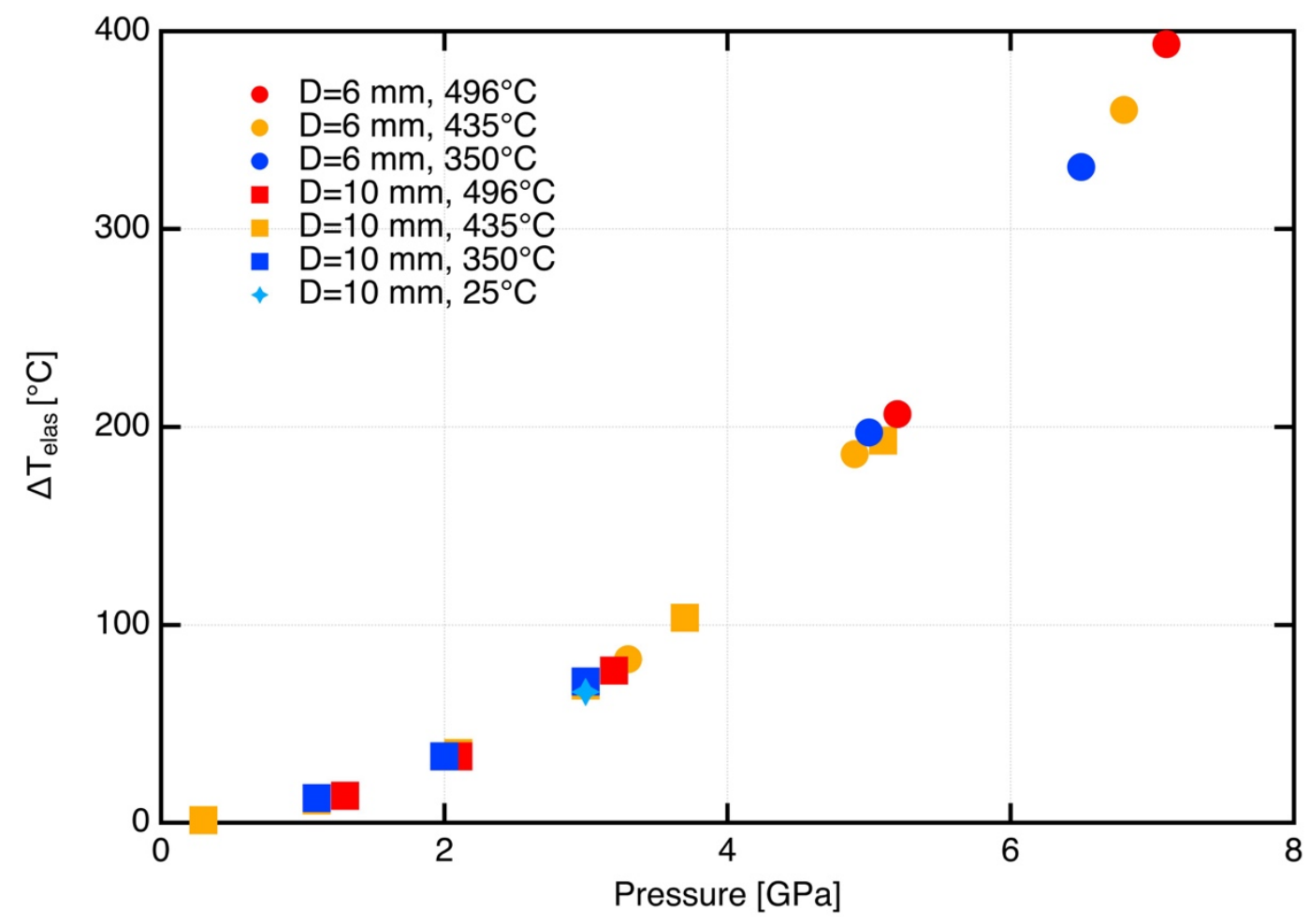

Fig.7 Calculated elastic energy induced temperature increase of SF6 glass as a function of pressure.

\subsection{Approach 2: shear yielding}

To account for the temperature influence on the yield stress, Raghavan et al. ${ }^{26}$ used the Arrhenius model

$$
Y=Y_{0} e^{\frac{E a}{R T}}
$$

In this work, we extend the Arrhenius equation to Eq. (15) by introducing an activation volume as has been reported in other studies 22,44 to account for the pressure effect.

$$
Y=Y_{0} e^{\frac{E_{a}+P V a}{R T}}
$$

where $Y_{0}$ is a hypothetical yield stress at infinite temperature, $E_{a}$ is the activation energy, 
and $V_{a}$ is the activation volume. To keep the model simple, we apply one set of constant $Y_{0}, E_{a}$ and $V_{a}$ parameters to fit all the yield stress data.

The experiments were performed at the same constant strain rate for two different sample diameters. Looking at the yield stress results in Table 1, the yield stress at $3 \mathrm{GPa}$ measured by different anvil setups achieved similar values, which indicate that the reproducibility of the results from the two different anvil setups is acceptable. The apparent activation energy $E_{a}$ can be determined from a linear fit to the plots in Fig.8 (a). The SF6 glass during HPT deformation exhibited very low activation energy of only around $1 \mathrm{~kJ} / \mathrm{mol}$ compared to the activation energy of $515 \mathrm{~kJ} / \mathrm{mol}$ at ambient pressure for viscous flow. Similarly, Fig.8 (b) is used to obtain the apparent activation volume $V_{a}$. The calculated $V_{a}$ varies from $1.16 \mathrm{~cm}^{3} / \mathrm{mol}$ to $2.06 \mathrm{~cm}^{3} / \mathrm{mol}$, which is close to the activation energy of SCHOTT N-BK $7^{\circledR}$ glass of $\sim 2 \mathrm{~cm}^{3} / \mathrm{mol}$ reported by Ding et al. ${ }^{22,23}$. Moreover, Fig.8 (b) shows that the yield stress increases with increasing pressure. 

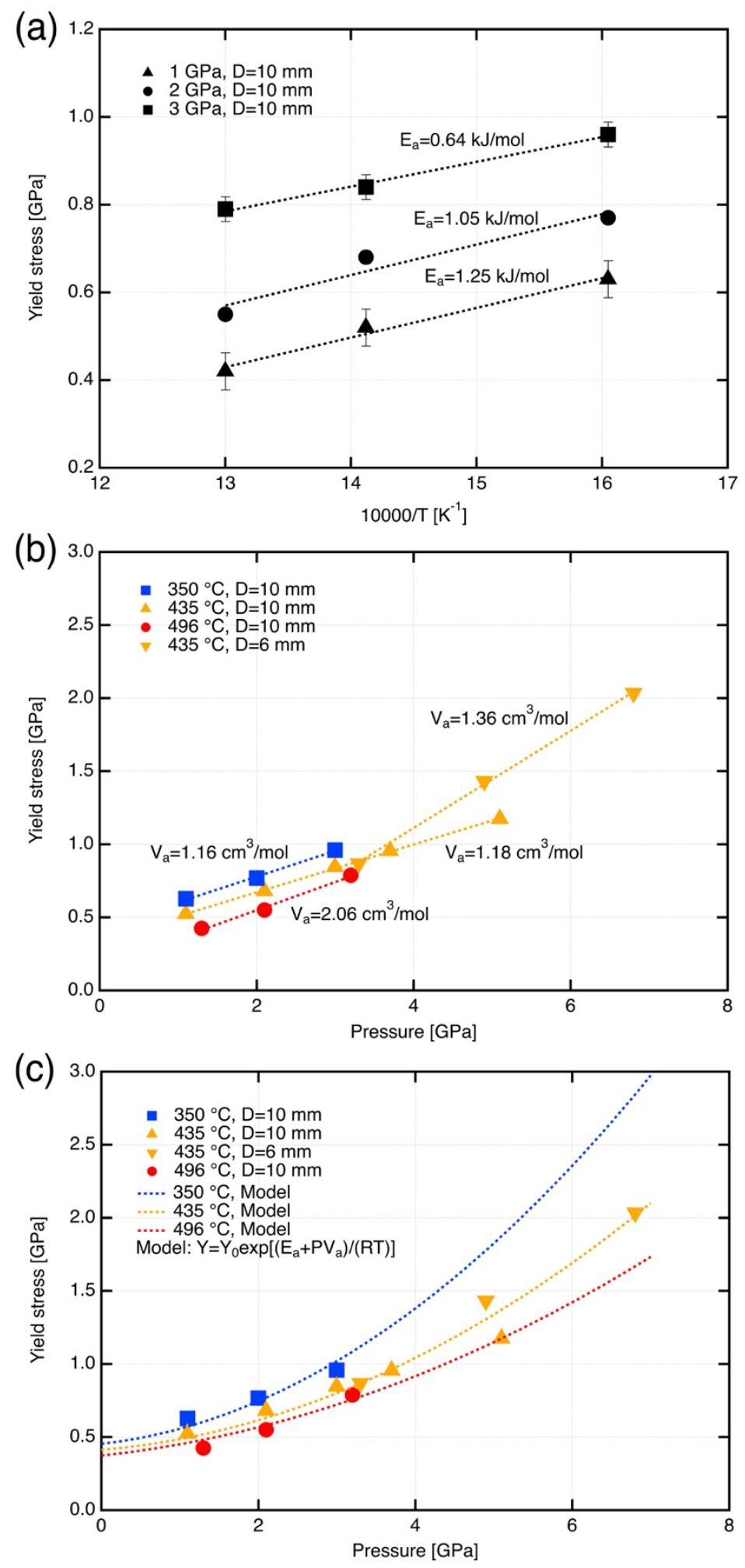

Fig.8 (a) Yield stress of SF6 glass deformed in HPT as a function of pressure to determine the apparent activation energy; (b) Temperature dependence of the yield stress to determine the apparent activation volume of SF6 glass during HPT deformation; (c) Yield stress calculated from the HPT measurements fitted by an Arrhenius type model. 
However, the SF6 glass samples deformed at $435{ }^{\circ} \mathrm{C}$ under $0.3 \mathrm{GPa}$ and at room temperature at $3 \mathrm{GPa}$ are not used to determine the fitting parameters of the proposed Arrhenius type model. For the former, the low pressure (by manual loading) might not suppress sliding as well as for the higher pressures. For the latter, we recall the big noise heard from the sample deformed at room temperature under $3 \mathrm{GPa}$. The big noise during the high-pressure loading indicates that a brittle fracture occurred, which opening the bulk glass sample and lower the torque. On the other hand, the cracking of glass generates various fine powders in the sample, which might be another important mechanism for glass flow at room temperature. Indeed, the particle size of glass influences the ability of the glass flow ${ }^{45}$.

To fit the experimental data, we employ a multidimensional unconstrained nonlinear minimization optimization algorithm (using the MATLAB function fminsearch ${ }^{46}$ ), to find the best-fit parameters for the model. Fig.8(c) displays that the Arrhenius type model can coarsely describe the experimental yield stress calculation with the parameters $Y_{0}=$ $0.17 \pm 0.01 \mathrm{GPa}, E_{a}=4.8 \pm 0.5 \mathrm{~kJ} / \mathrm{mol}$ and $V_{a}=1.4 \pm 0.2 \mathrm{~cm}^{3} / \mathrm{mol}$. The best-fit activation energy is slightly higher than the calculation in Fig. 8 (a), and the best-fit activation volume is in agreement with the calculation in Fig.8 (b). The model also extrapolates the yield stress at ambient pressure decreases with increasing temperatures, with $\sim 0.44 \mathrm{GPa}$ at $350{ }^{\circ} \mathrm{C}, \sim 0.39 \mathrm{GPa}$ at $435{ }^{\circ} \mathrm{C}$, and $0.37 \mathrm{GPa}$ at $496{ }^{\circ} \mathrm{C}$, respectively. We note that the fitting is only in coarse agreement with the experimental data, and some 
slight differences remain in the slope of the experimental data and model, which may result from systematic deviations. Yet the model is better than the other explanations even in its basic version.

\subsubsection{Pure friction?}

Considering that all the deformation experiments exhibit similar activation energy, one other possible reason could be sliding between the glass samples and anvils. The friction coefficient determined according to Eq. (7) and plotted in Fig.9 apparently decreases with increasing temperature in the $10 \mathrm{~mm}$ anvils setup and is thus not a possible explanation for the torques measured. Furthermore, the samples (even for the $0.3 \mathrm{GPa}$ case at least at one sample side) showed well surface characteristics/markings of the anvil, most notably scratches. This is a strong indication that in this area no sliding was present and that thus the overall amount of sliding should not be dominant. 


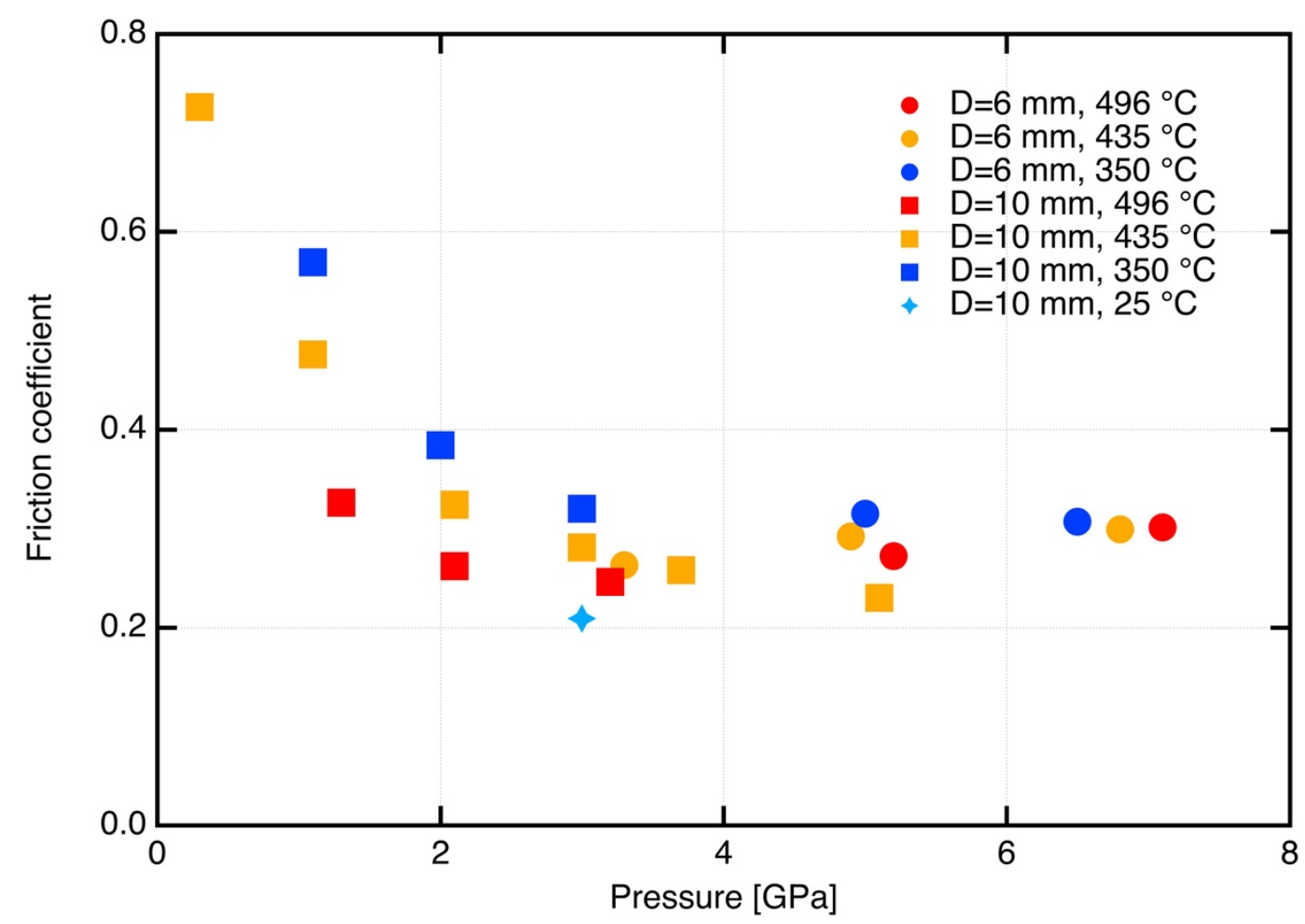

Fig.9 Friction coefficient of SF6 glass as a function of pressure in HPT.

\section{Conclusions}

Deformation experiments were performed on SCHOTT SF6 ${ }^{\circledR}$ in an HPT apparatus under high pressure and different temperatures. From several approaches tested, the mechanism of plastic shear yielding during the HPT experiments on SF6 offers the most likely explanation for the measured results. This yield stress of SF6 glass decreases with increasing temperature and decreasing pressure. An extended Arrhenius model was applied and shown that it can explain the experimental results of SF6 glass, with some short-comings.

\section{Acknowledgments}

Linfeng Ding is funding by the European Union's Horizon 2020 research and 
innovation program under the Marie Sklodowska-Curie grant agreement No 642029. The authors thank the technicians and engineers at the SCHOTT machine-shop for the sample preparation.

\section{References}

1. Zheng QJ, Mauro JC. Viscosity of glass-forming systems. J Am Ceram Soc. $2017 ; 100(1): 6-25$.

2. Fulcher GS. Analysis of recent measurements of the viscosity of glasses. J Am Ceram Soc. 1925;8(6):339-355.

3. Williams ML, Landel RF, Ferry JD. The temperature dependence of relaxation mechanisms in amorphous polymers and other glass-forming liquids. J Am Chem Soc. 1955;77(14):3701-3707.

4. Cohen MH, Turnbull D. Molecular transport in liquids and glasses. J Chem Phys. 1959;31(5):1164-1169.

5. Greet RJ, Turnbull D. Test of adam-gibbs liquid viscosity model with o-terphenyl specific-heat data. J Chem Phys. 1967;47(6):2185-2190.

6. Turnbull D, Cohen MH. On the free-volume model of the liquid-glass transition. The journal of chemical physics. 1970;52(6):3038-3041.

7. Adam G, Gibbs JH. On the temperature dependence of cooperative relaxation properties in glass-forming liquids. The Journal of Chemical Physics. 1965;43(1):139146.

8. Mauro JC, Yue YZ, Ellison AJ, Gupta PK, Allan DC. Viscosity of glass-forming liquids. 
P Natl Acad Sci USA. 2009;106(47):19780-19784.

9. Peter K. Densification and flow phenomena of glass in indentation experiments. Journal of Non-Crystalline Solids. 1970;5(2):103-115.

10. Shang HX, Rouxel T. Creep behavior of soda-lime glass in the 100-500 k temperature range by indentation creep test. J Am Ceram Soc. 2005;88(9):2625-2628.

11. To T, Célarié F, Roux-Langlois C, Bazin A, Gueguen Y, Orain H, et al. Fracture toughness, fracture energy and slow crack growth of glass as investigated by the singleedge precracked beam (sepb) and chevron-notched beam (cnb) methods. Acta Mater. 2018;146:1-11.

12. Lee EH, Radok JRM. The contact problem for viscoelastic bodies. Journal of Applied Mechanics. 1960;27(3):438-444.

13. Alkorta J, Martinez-Esnaola JM, Sevillano JG. Absence of one-to-one correspondence between elastoplastic properties and sharp-indentation load-penetration data. J Mater Res. 2005;20(5):1369-1369.

14. Cook RL, King HE, Herbst CA, Herschbach DR. Pressure and temperature dependent viscosity of two glass forming liquids: Glycerol and dibutyl phthalate. The Journal of Chemical Physics. 1994;100(7):5178.

15. Sperry L, JD M. Pressure dependence of viscosity of b2o3. Phys Chem Glasses. 1968;9(3):91-95.

16. Schulze F, Behrens H, Hurkuck W. Determination of the influence of pressure and dissolved water on the viscosity of highly viscous melts: Application of a new parallel- 
plate viscometer. Am Mineral. 1999;84(10):1512-1520.

17. Tribone JJ, Oreilly JM, Greener J. Pressure-jump volume-relaxation studies of polystyrene in the glass-transition region. J Polym Sci Pol Phys. 1989;27(4):837-857.

18. Hodge IM. Enthalpy relaxation and recovery in amorphous materials. Journal of NonCrystalline Solids. 1994;169(3):211-266.

19. Simon SL, Park JY, McKenna GB. Enthalpy recovery of a glass-forming liquid constrained in a nanoporous matrix: Negative pressure effects. Eur Phys J E. 2002;8(2):209-216.

20. Grassia L, Simon SL. Modeling volume relaxation of amorphous polymers: Modification of the equation for the relaxation time in the kahr model. Polymer. 2012;53(16):3613-3620.

21. Avramov I. Pressure dependence of viscosity of glassforming melts. Journal of NonCrystalline Solids. 2000;262(1-3):258-263.

22. Ding L, Buhre S, Kunisch C, Kaus B. Pressure dependence of density and structural relaxation of glass near the glass transition region. J Am Ceram Soc. 2018;101(3):11491158

23. Ding L, Thieme M, Demouchy S, Kunisch C, Kaus BJP. Effect of pressure and temperature on viscosity of a borosilicate glass. J Am Ceram Soc. 2018;0(0):1-11.

24. Paterson M. Rock deformation experimentation. Geophysical monograph. 1990:187194.

25. Nanzai Y. Molecular kinetics of yield deformation and ductile fracture in polymer 
glasses. Prog Polym Sci. 1993;18(3):437-479.

26. Raghavan R, Harzer TP, Chawla V, Djaziri S, Phillipi B, Wehrs J, et al. Comparing small scale plasticity of copper-chromium nanolayered and alloyed thin films at elevated temperatures. Acta Mater. 2015;93:175-186.

27. Vaidyanathan R, Dao M, Ravichandran G, Suresh S. Study of mechanical deformation in bulk metallic glass through instrumented indentation. Acta Mater. 2001;49(18):37813789.

28. Donovan PE. A yield criterion for pd40ni40p20 metallic-glass. Acta Metall Mater. 1989;37(2):445-456.

29. Schuh CA, Lund AC. Atomistic basis for the plastic yield criterion of metallic glass. Nat Mater. 2003;2(7):449-452.

30. Demetriou MD, Launey ME, Garrett G, Schramm JP, Hofmann DC, Johnson WL, et al. A damage-tolerant glass. Nat Mater. 2011;10(2):123-128.

31. Xi XK, Zhao DQ, Pan MX, Wang WH, Wu Y, Lewandowski JJ. Fracture of brittle metallic glasses: Brittleness or plasticity. Phys Rev Lett. 2005;94(12).

32. Inoue A, Shen BL, Koshiba H, Kato H, Yavari AR. Cobalt-based bulk glassy alloy with ultrahigh strength and soft magnetic properties. Nat Mater. 2003;2(10):661-663.

33. Zhilyaev AP, Nurislamova GV, Kim BK, Baro MD, Szpunar JA, Langdon TG. Experimental parameters influencing grain refinement and microstructural evolution during high-pressure torsion. Acta Mater. 2003;51(3):753-765.

34. Vorhauer A, Pippan R. On the homogeneity of deformation by high pressure torsion. 
Scripta Mater. 2004;51(9):921-925.

35. Bachmaier A, Kerber M, Setman D, Pippan R. The formation of supersaturated solid solutions in fe-cu alloys deformed by high-pressure torsion. Acta Mater. 2012;60(3):860871.

36. Xu W, Edwards D, Wu X, Stoica M, Calin M, Kühn U, et al. Promoting nano/ultrafineduplex structure via accelerated $\alpha$ precipitation in a $\beta$-type titanium alloy severely deformed by high-pressure torsion. Scripta Mater. 2013;68(1):67-70.

37. Heiman D, Hamilton DS, Hellwarth RW. Brillouin-scattering measurements on optical-glasses. Physical Review B. 1979;19(12):6583-6592.

38. Hundertmark H, Rammler S, Wilken T, Holzwarth R, Hansch TW, Russell PS. Octave-spanning supercontinuum generated in sf6-glass pcf by a $1060 \mathrm{~nm}$ mode-locked fibre laser delivering 20 pj per pulse. Opt Express. 2009;17(3):1919-1924.

39. Fu B, Li SG, Yao YY, Zhang L, Zhang MY. Supercontinuum generation with high birefringence sf6 soft glass photonic crystal fibers. Chinese Phys Lett. 2010;27(7).

40. Efimov A, Taylor AJ. Supercontinuum generation and soliton timing jitter in sf6 soft glass photonic crystal fibers. Opt Express. 2008;16(8):5942-5953.

41. Wetscher F, Vorhauer A, Pippan R. Strain hardening during high pressure torsion deformation. Mat Sci Eng a-Struct. 2005;410:213-216.

42. Edalati K, Miresmaeili R, Horita Z, Kanayama H, Pippan R. Significance of temperature increase in processing by high-pressure torsion. Mat Sci Eng a-Struct. 2011;528(24):7301-7305. 
43. Zhilyaev AP, Langdon TG. Reassessment of temperature increase and equivalent strain calculation during high-pressure torsion. Iop Conf Ser-Mat Sci. 2014;63.

44. Jin HJ, Gu XJ, Wen P, Wang LB, Lu K. Pressure effect on the structural relaxation and glass transition in metallic glasses. Acta Mater. 2003;51(20):6219-6231.

45. Wong ACY. Characterisation of the flowability of glass beads by bulk densities ratio. Chem Eng Sci. 2000;55(18):3855-3859.

46. Lagarias JC, Reeds JA, Wright MH, Wright PE. Convergence properties of the neldermead simplex method in low dimensions. Siam J Optimiz. 1998;9(1):112-147. 
Table 1 Experimental conditions and results

\begin{tabular}{|c|c|c|c|c|c|c|c|c|c|c|}
\hline Samples & $\begin{array}{l}\text { Glass } \\
\text { type }\end{array}$ & $\begin{array}{c}\text { Diameter } \\
{[\mathrm{mm}]}\end{array}$ & $\begin{array}{c}\text { Thickness } \\
{[\mathrm{mm}]}\end{array}$ & $\begin{array}{c}\text { Pressure } \\
\text { [GPa }]\end{array}$ & $\begin{array}{c}\text { Temperature } \\
{\left[{ }^{\circ} \mathrm{C}\right]}\end{array}$ & $\begin{array}{l}\text { Torque } \\
{[\mathrm{N} \cdot \mathrm{m}]}\end{array}$ & $\begin{array}{c}\text { Viscosity } \\
\log _{10}[\mathrm{~Pa} \cdot \mathrm{s}]\end{array}$ & $\begin{array}{c}\text { Yield stress } \\
\text { [GPa }]\end{array}$ & $\begin{array}{l}\text { Repeat } \\
\text { times }\end{array}$ & Note \\
\hline $\mathrm{S} 1$ & SF6 & 6 & $0.54 \pm 0.02$ & $3.3 \pm 0.1$ & $435 \pm 5$ & $49 \pm 1$ & $11.32 \pm 0.02$ & $0.87 \pm 0.02$ & 4 & \\
\hline $\mathrm{S} 2$ & SF6 & 6 & $0.54 \pm 0.02$ & $5.2 \pm 0.1$ & $496 \pm 5$ & $80 \pm 1$ & $11.53 \pm 0.02$ & $1.41 \pm 0.02$ & 4 & \\
\hline $\mathrm{S} 3$ & SF6 & 6 & $0.54 \pm 0.02$ & $4.9 \pm 0.1$ & $435 \pm 5$ & $81 \pm 1$ & $11.53 \pm 0.02$ & $1.43 \pm 0.02$ & 4 & \\
\hline $\mathrm{S} 4$ & SF6 & 6 & $0.54 \pm 0.02$ & $5.0 \pm 0.1$ & $350 \pm 5$ & $89 \pm 1$ & $11.58 \pm 0.02$ & $1.57 \pm 0.02$ & 4 & \\
\hline S5 & SF6 & 6 & $0.54 \pm 0.02$ & $7.1 \pm 0.1$ & $496 \pm 5$ & $121 \pm 2$ & $11.71 \pm 0.02$ & $2.14 \pm 0.04$ & 4 & \\
\hline S6 & SF6 & 6 & $0.54 \pm 0.02$ & $6.8 \pm 0.1$ & $435 \pm 5$ & $115 \pm 1$ & $11.68 \pm 0.02$ & $2.03 \pm 0.02$ & 4 & \\
\hline S7 & SF6 & 6 & $0.54 \pm 0.02$ & $6.5 \pm 0.1$ & $350 \pm 5$ & $113 \pm 2$ & $11.68 \pm 0.02$ & $2.00 \pm 0.04$ & 4 & \\
\hline S8 & SF6 & 10 & $0.54 \pm 0.02$ & $0.3 \pm 0.0$ & $435 \pm 5$ & $57 \pm 3$ & $10.49 \pm 0.02$ & $0.22 \pm 0.01$ & 3 & Manual \\
\hline S9 & SF6 & 10 & $0.54 \pm 0.02$ & $1.3 \pm 0.1$ & $496 \pm 5$ & $111 \pm 5$ & $10.78 \pm 0.05$ & $0.42 \pm 0.02$ & 3 & \\
\hline $\mathrm{S} 10$ & SF6 & 10 & $0.54 \pm 0.02$ & $1.1 \pm 0.1$ & $435 \pm 5$ & $137 \pm 2$ & $10.87 \pm 0.01$ & $0.52 \pm 0.01$ & 3 & \\
\hline $\mathrm{S} 11$ & SF6 & 10 & $0.54 \pm 0.02$ & $1.1 \pm 0.1$ & $350 \pm 5$ & $164 \pm 3$ & $10.95 \pm 0.03$ & $0.63 \pm 0.01$ & 3 & \\
\hline $\mathrm{S} 12$ & SF6 & 10 & $0.54 \pm 0.02$ & $2.1 \pm 0.1$ & $496 \pm 5$ & $144 \pm 4$ & $10.90 \pm 0.02$ & $0.55 \pm 0.02$ & 3 & \\
\hline S13 & SF6 & 10 & $0.54 \pm 0.02$ & $2.1 \pm 0.1$ & $435 \pm 5$ & $178 \pm 2$ & $10.99 \pm 0.01$ & $0.68 \pm 0.01$ & 3 & \\
\hline $\mathrm{S} 14$ & SF6 & 10 & $0.54 \pm 0.02$ & $2.0 \pm 0.1$ & $350 \pm 5$ & $201 \pm 3$ & $11.04 \pm 0.01$ & $0.77 \pm 0.01$ & 3 & \\
\hline $\mathrm{S} 15$ & SF6 & 10 & $0.54 \pm 0.02$ & $3.2 \pm 0.1$ & $496 \pm 5$ & $206 \pm 4$ & $11.05 \pm 0.02$ & $0.79 \pm 0.02$ & 3 & \\
\hline S16 & SF6 & 10 & $0.54 \pm 0.02$ & $3.0 \pm 0.1$ & $435 \pm 5$ & $221 \pm 3$ & $11.08 \pm 0.01$ & $0.84 \pm 0.01$ & 3 & \\
\hline S17 & SF6 & 10 & $0.54 \pm 0.02$ & $3.0 \pm 0.1$ & $350 \pm 5$ & $251 \pm 2$ & $11.14 \pm 0.02$ & $0.96 \pm 0.01$ & 3 & \\
\hline $\mathrm{S} 18$ & SF6 & 10 & $0.54 \pm 0.02$ & $3.0 \pm 0.1$ & 25 & $164 \pm 2$ & $10.95 \pm 0.01$ & $0.63 \pm 0.01$ & 2 & Room T \\
\hline
\end{tabular}




\begin{tabular}{rrrrrrrrrrr} 
S19 & SF6 & 10 & $0.54 \pm 0.02$ & $3.7 \pm 0.1$ & $435 \pm 5$ & $250 \pm 2$ & $11.14 \pm 0.01$ & $0.95 \pm 0.01$ & 2 \\
S20 & SF6 & 10 & $0.54 \pm 0.02$ & $5.1 \pm 0.1$ & $435 \pm 5$ & $307 \pm 3$ & $11.23 \pm 0.03$ & $1.17 \pm 0.01$ & 2 \\
S21 & SF6 & 10 & $0.54 \pm 0.02$ & $7.4 \pm 0.2$ & $435 \pm 5$ & $776 \pm 9$ & $11.63 \pm 0.02$ & $2.96 \pm 0.03$ & 1 & Anvils \\
S22 & SF6 & 10 & $0.62 \pm 0.02$ & $0.3 \pm 0.0$ & $435 \pm 5$ & $50 \pm 15$ & $10.50 \pm 0.12$ & $0.19 \pm 0.06$ & 1 & Flat anvils \\
\hline
\end{tabular}

